\title{
A urological challenge: Voiding dysfunction in multiple sclerosis
}

\author{
Jacques Corcos, MD, FRSCS
}

Professor of Surgery (Urology), McGill University, Montreal, QC

Cite as: Can Urol Assoc J 2013;7(9-10):S181-2. http://dx.doi.org/10.5489/cuaj.1618

Published online October 9, 2013.

\section{Abstract}

Patients with multiple sclerosis (MS) have a very high prevalence of lower urinary tract symptoms. This summary provides a brief overview of MS epidemiology, pathophysiology, the impact of the disease on patient quality of life, and the particular kinds of urinary tract abnormalities and symptoms that can present among patients with MS. Strategies to help diminish the impact of these symptoms are also discussed.

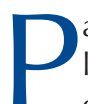

atients with multiple sclerosis (MS) have a very high prevalence of lower urinary tract symptoms-as many as $90 \%$ of patients with MS experience some form of voiding dysfunction and/or incontinence. ${ }^{1} \mathrm{MS}$ is most commonly diagnosed among patients aged 20 to 50 years, with the ratio of women to men approximately two to one. Individuals with the disease experience a loss of neural conduction along axonal pathways through autoimmune-driven demyelination. Resultant edema also worsens the neurologic impairment. Over time, chronic attacks lead to scarring of nerves, which leads to severe and often permanent neurologic dysfunction. The pattern of these attacks varies, as there are four subtypes of MS: relapsing-remitting, secondary progressive, primary progressive and progressive-relapsing. The majority of patients fall into the relapsing-remitting subtype.

Depending on the region of the central nervous system affected, patients with MS present with a wide variety of neurologic symptoms. MS-associated damage in the brain can result in cognitive impairment, sensory and motor deficits, depression and epilepsy. Optic nerve damage is common, with painful loss of vision the result. Neuronal damage to the pons can result in clumsiness, poor balance, diplopia, vertigo, swallowing problems or weakness, while spinal cord damage in MS is associated with stiffness, paroxysmal spasms and weakness.

\section{Pathophysiology of LUTS in MS}

With respect to lower urinary tract symptoms (LUTS), brain deficits can also lead to loss of voluntary control of initiation and detrusor overactivity.

Other LUTS secondary to MS are mediated by axonal damage in the pons and the spinal cord. The lateral corticospinal and reticulospinal cords, in particular, are responsible for innervation of the lower urinary tract. ${ }^{2}$ Damage to these pathways can result in detrusor-external sphincter dyssynergia (DESD), detrusor overactivity (DO) and detrusor hypocontractility. These are the most common findings of urodynamic studies among patients with MS.

\section{Prevalence of LUTS in MS}

Patients with MS can experience any number of LUTS, including urgency, frequency, incontinence, hesitancy and retention (Table 1). ${ }^{3,4}$ It is uncommon that a urinary tract symptom would be the presenting complaint that leads to a diagnosis of MS (fewer than $10 \%$ ), but it does happen.

A review of studies reporting prevalence of LUTS among patients with MS showed that the prevalence of urgency ranged from 60 to $86 \%$, frequency from 50 to $83 \%$, incontinence from 19 to $83 \%$, hesitancy from 28 to $58 \%$ and retention from 2 to $20 \%$.

\section{Management of LUTS in MS}

The urologic evaluation in patients with MS should include the basic clinical evaluation (including impact analysis and degree of bother), basic physical examination (including stress test in women), urinalysis (with or without culture and sensitivity) and urodynamic studies.

A number of treatment options can be used for LUTS in the setting of MS. Anticholinergic medications can be used to treat symptoms of urgency and incontinence. A 2012 review of studies evaluating antimuscarinics for the treatment of overactive bladder showed that solifenacin, oxybutynin and propiverine were associated with the best numerical reductions in incontinence episodes per 24 hours of all the antimuscarinics examined (not an MS-specific analysis). ${ }^{7}$ 


\begin{tabular}{|c|c|c|c|c|c|c|}
\hline Study & No. patients & Urgency & Frequency & Incontinence & Hesitancy & Retention \\
\hline Miller $1965^{13}$ & 321 & 60 & 50 & 36 & 33 & 2 \\
\hline Bradley $1973^{14}$ & 90 & 86 & 60 & - & 28 & 20 \\
\hline Hennessey ${ }^{15}$ & 99 & 191 & 71 & 76 & 19 & 48 \\
\hline Ukkonen $2004^{16}$ & 24 & 3 & 54 & 75 & 58 & - \\
\hline Quarto $2007^{4}$ & 107 & 61 & 83 & 32 & - & - \\
\hline
\end{tabular}

*Modified from Fernandez et al. ${ }^{3}$ and Quarto et al. ${ }^{4}$

For DO, counselling on lifestyle habits and training on pelvic floor exercises are the backbone of therapy. Antimuscarinics may also help with DO-related symptoms. Botulinum toxin A has also been examined among patients with neurologic problems (mixed populations of MS and spinal cord injury). ${ }^{8-10}$ In these studies, more than half the patients treated experienced significant improvement in symptoms. Indeed, as many as $76 \%$ of patients in one trial achieved complete continence. ${ }^{10}$

Although surgery is not typically used to address LUTS in the setting of MS, midurethral slings may be helpful.

Neuromodulation can also be considered for DO. Posterior tibial nerve stimulation has demonstrated substantial efficacy in the setting of MS. ${ }^{11}$ Daily 20-minute sessions of transcutaneous posterior tibial nerve stimulation (TPTNS) led to clinical improvement (urgency, incontinence, frequency) in $82.6 \%$ and $83.3 \%$ at day 30 and day 90, respectively. Cystometric response to TPTNS was positive in $51.2 \%$ (increase of $>30 \%$ of cystometric capacity and/or reflex volume). ${ }^{11}$ There is less compelling evidence for the use of sacral nerve stimulation, although promising results have been demonstrated in a small series of nine patients. ${ }^{12}$

For patients with hypo/atonic bladder, drainage is necessary if there are bothersome post-void symptoms. Clean intermittent catheterization $(\mathrm{CIC})$ is preferred when possible, while in-dwelling catheters or suprapubic (SP) tubes are other options (patients overwhelmingly prefer the latter). Notably, neuromodulation is not an option in this scenario, as it addresses pelvic floor/sphincter overactivity and not hypotonic bladder.

The most challenging aspect of treatment of LUTS in MS is addressing DESD, particularly when accompanied by DO. Individually tailored treatment may include biofeedback, treatment with alpha-blockers, myorelaxants, antimuscarinics and/or botulinum toxin injections (both in the bladder and the sphincter).

\section{Conclusions}

LUTS are common, nearly ubiquitous complications of MS. Urologists and urogynecologists can benefit from enriching their understanding of the pathophysiology and complications associated with this disease. The modalities used to treat LUTS in this setting are similar to those used in other populations, although treatment success may be more elusive, particularly among those with both DESD and DO.

Competing interests: This article is part of a CUAJ supplement sponsored by Astellas Pharma Canada, Inc. Dr. Corcos has received speaker fees, educational grants, and/or travel assistance from Allergan, Astellas, AstraZeneca, and Paladin.

\section{References}

1. Leboeuf L, Cohen B, Gousse AE. Multiple sclerosis. In: Corcos J, Schick E, eds. Textbook of the Neurogenic Bladder. CRC Press 2008:294-311. hittp://dx.doi.org/10.3109/9781439805046-27

2. Oppenheimer DR. The cervical cord in multiple sclerosis. Neuropathol Appl Neurobiol 1978;4:151-62. http://dx.doi.org/10.1111/i.1365-2990.1978.tb00555.x

3. Fernandez 0 . Mechanisms and current treatments of urogenital dysfunction in multiple sclerosis. J Neurol 2002;249:1-8. http://dx.doi.org/10.1007/PL00007835

4. Quarto G, Autorino R, Gallo A, et al. Quality of life in women with multiple sclerosis and overactive bladder syndrome. Int Urogynecol J Pelvic Floor Dysfunct 2007;18:189-94. http://dx.doi.org/10.1007/ s00192-006-0131-9

5. Ebers GC, Sadovnick AD, Risch NJ. A genetic basis for familial aggregation in multiple sclerosis. Canadian Collaborative Study Group. Nature 1995;377:150-1. http://dx.doi.org/10.1038/377150a0

6. Poser CM. The epidemiology of multiple sclerosis: a general overview. Anne Neurol 1994;36:5180-93. http://dx.doi.org/10.1002/ana.410360805

7. Buser $N$, Ivic $S$, Kessler TM, et al. Efficacy and adverse events of antimuscarinics for treating overactive bladder: network meta-analyses. Eur Urol 2012;62:1040-60. http://dx.doi.org/10.1016/j. eururo.2012.08.060

8. Cruz F, Herschorn $S$, Aliotta $\mathrm{P}$, et al. Efficacy and safety of onabotulinumtoxinA in patients with urinary incontinence due to neurogenic detrusor overactivity: a randomised, double-blind, placebo-controlled trial. Eur Urol 2011;60:742-50. http://dx.doi.org/10.1016/i.eururo.2011.07.002

9. Herschorn S, Gajewski J, Ethans K, et al. Efficacy of botulinum toxin A injection for neurogenic detrusor overactivity and urinary incontinence: a randomized, double-blind trial. J Urol 2011;185:2229-35. http:// dx.doi.org/10.1016/i.juro.2011.02.004

10. Khan S, Game X, Kalsi V, et al. Long-term effect on quality of life of repeat detrusor injections of botulinum neurotoxin-A for detrusor overactivity in patients with multiple sclerosis. J Urol 2011;185:1344-9. http:// dx.doi.org/10.1016/i.juro.2010.12.002

11. de Sèze $M$, Raibaut $P$, Gallien $P$, et al. Transcutaneous posterior tibial nerve stimulation for treatment of the overactive bladder syndrome in multiple sclerosis: results of a multicenter prospective study. Neurourol Urodyn 2011;30:306-11. http://dx.doi.org/10.1002/nau.20958

12. Chartier-Kastler EJ, Ruud Bosch JL, Perrigot M, et al. Long-term results of sacral nerve stimulation (S3) for the treatment of neurogenic refractory urge incontinence related to detrusor hyperreflexia. J Urol 2000;164:1476-80. http://dx.doi.org/10.1016/S0022-5347(05)67010-3

13. Miller H, Simpson CA, Yeates WK. Bladder dysfunction in multiple sclerosis. Br Med J 1965; 1 (5445):12659.

14. Bradley WE, Logothetis JL, Timm GW. Cystometric and sphincter abnormalities in multiple sclerosis. Neurology 1973;23(10):1131-9.

15. Hennessey A, Robertson NP, Swingler R, et al. Urinary, faecal and sexual dysfunction in patients with multiple sclerosis. J Neurol 1999;246(11):1027-32.

16. Ukkonen $M$, Elovaara I, Dastidar $\mathrm{P}$, et al. Urodynamic findings in primary progressive multiple sclerosis are associated with increased volumes of plaques and atrophy in the central nervous system. Acta Neurol Scand 2004;109:100-5. http://dx.doi.org/10.1034/i

Correspondence: Dr. Jacques Corcos, Jewish General Hospital, 3755 Cote Ste. Catherine Road, Suite E211, Montreal, QC H3T 1E2; fax: 514-340-7559; icorcos@uro.jgh.mcgill.ca 